\title{
El paisaje de los dioses: los santuarios griegos de la época clásica y su entorno natural
}

\section{The gods' landscape: Greek sanctuaries of classic age and their natural environment}

\author{
Ronald Harris Diez \\ Instituto de Estética. Pontificia Universidad Católica de Chile \\ rharris@uc.cl
}

\begin{abstract}
(2)
Resumen • El presente artículo busca profundizar y poner en evidencia la relación que se establece y determina en el emplazamiento de un santuario griego en un particular entorno natural, para lo cual se centra en tres puntos principales: el genius loci, el antecedente mítico-histórico y el buscado contraste entre las formas arquitectónicas y las naturales.
\end{abstract}

Palabras clave: templo griego, santuario, témenos, genius loci, hierofanía.

Abstract • This essay seeks to characterize the relationship between several factors involved in the settlement of a Greek sanctuary in a specific natural environment. The paper will focus on three main aspects of the sanctuary: the genius loci, the historical and mythical precedents, and the intentional contrast among the architectural and the natural forms.

Keywords: Greek Temple, Sanctuary, Temenos, Genius Loci, Hierophany.

¿Cómo podemos hablar del mundo griego, de su particular visión, si las ciudades Estado que lo componían eran tan disímiles y estaban en permanentes disputas entre sí? La cosmovisión común estaba dada por una lengua y una religión compartidas. En tal sentido, los templos que salpicaban el paisaje griego cumplían el relevante rol de simbolizar esa doble unión, la de los pueblos entre sí y la de éstos con sus dioses, y cuando hablamos del paisaje griego no nos remitimos solamente a Grecia, sino también a la gran cantidad de colonias que dicho pueblo tenía repartidas en torno al Mediterráneo. 


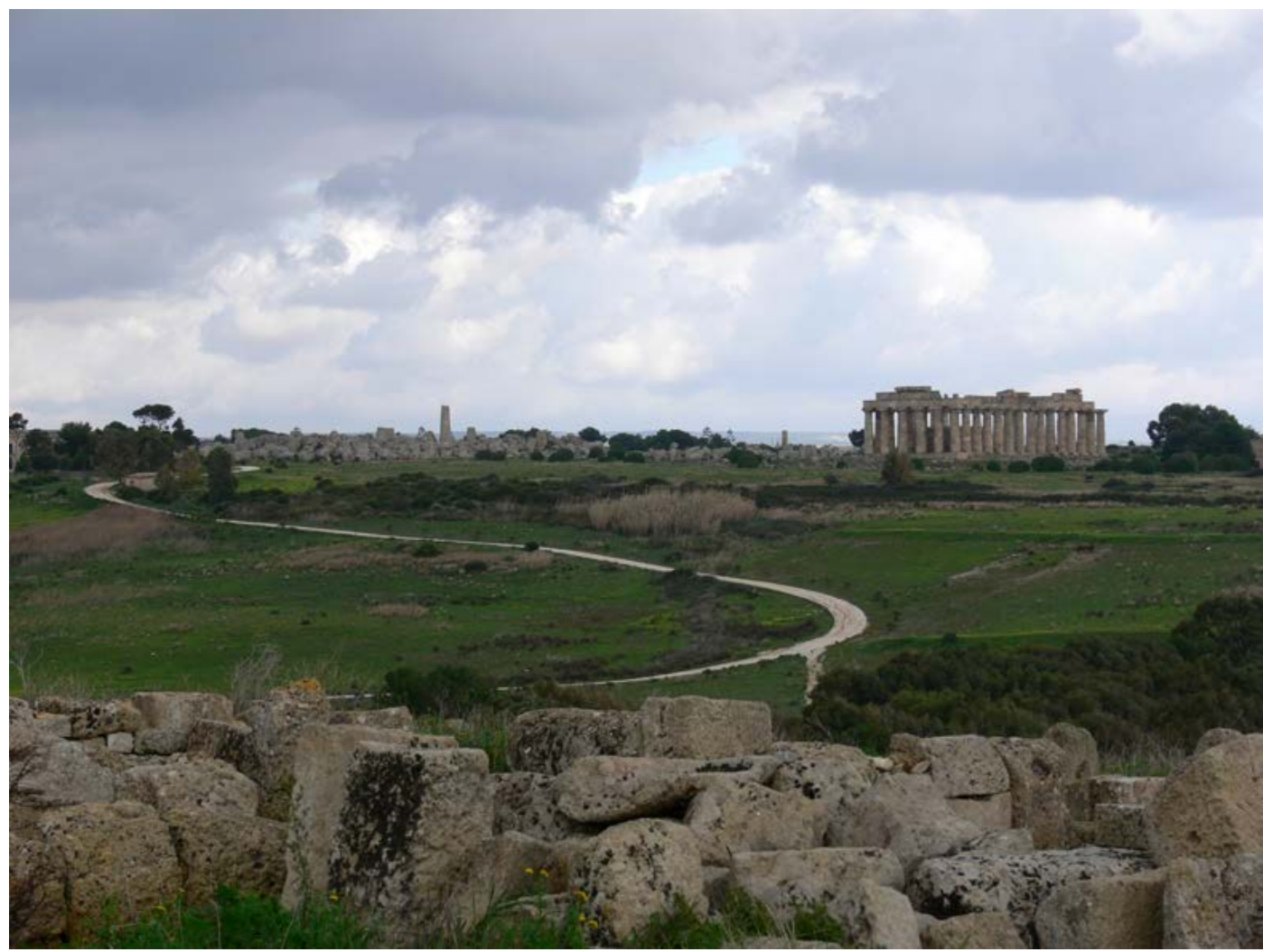

Imagen 1. En la colina oriental, más allá de los muros que destacan en primer plano, se emplazan los templos de la zona sacra de Selinus', hoy Selinunte, Sicilia, Italia. Fuente: fotografía del autor.

El templo griego no era para el hombre, no se entendía el edificio como un lugar de congregación para fieles; era la "casa de un dios» y en su interior se encontraba su «simulacro $»^{2}$. Por consiguiente el templo debía estar separado del hombre, constituyendo por sí mismo, dentro del paisaje, una imagen de las cualidades del dios al que estaba consagrado (Scully). Los fieles, ya desde épocas prehelénicas, solían realizar sus sacrificios en altares al aire libre, en contacto directo con las fuerzas de la naturaleza que encarnaban a sus dioses y, en el caso particular de los griegos, sus aras se encontraban normalmente enfrentando el templo ${ }^{3}$.

Selinus era una colonia de ultramar de la ciudad ática de Megara Hiblea, al igual que lo fuera originalmente Bizancio.

Generalmente era una escultura o un elemento que simbolizaba al dios.

El acceso al templo habitualmente se orientaba hacia el Este, y es frente a su fachada donde generalmente se ubicaba el altar. Los sacrificios solían realizarse por la mañana, cuando los primeros rayos del sol penetraban la naos (sala principal del templo) a través de las puertas abiertas, iluminando la imagen del dios que se hacía visible a los que que se encontraban en el altar. 


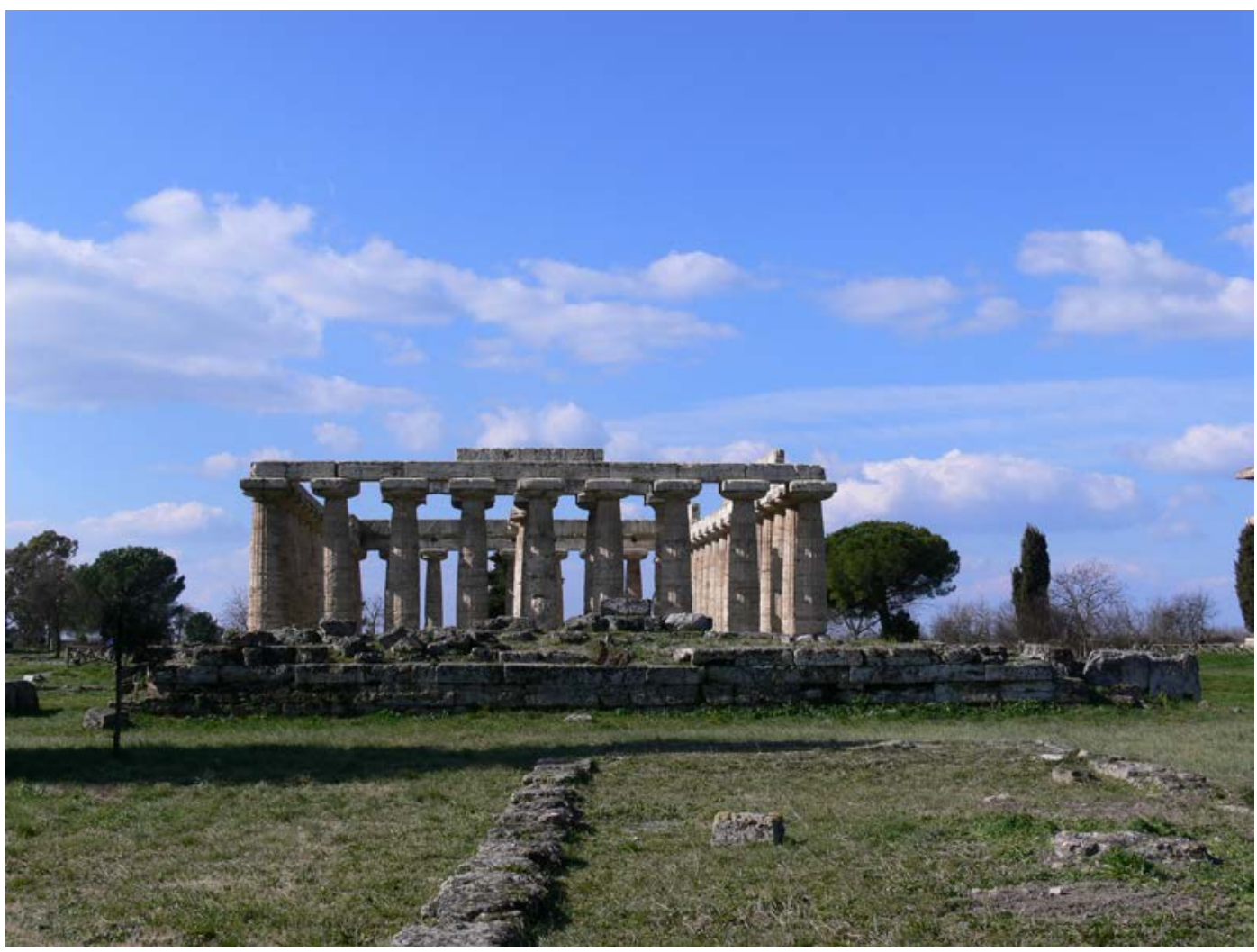

Imagen 2. Vista frontal del templo conocido como la Basílica, que data del 540 a.C. y que al parecer estaba consagrado a la diosa Hera. En primer plano se aprecian los restos del altar de los sacrificios que se erigía, siguiendo la tradición, frente al edificio sacro. Paestum, la antigua colonia de ultramar de Posidonia, Campania, Italia. Fuente: fotografía del autor.

Es evidente que en los estudios historiográficos respecto de la arquitectura griega, el templo se ha considerado como una estructura aislada y estéticamente mensurable en términos de su propia forma, desconectado del paisaje que lo rodea. Como deduciremos al finalizar el presente trabajo, el templo que nace producto de idealizaciones matemáticas abstractas se concretiza cuando encuentra su lugar en la naturaleza; es en medio de ese paisaje que se hace acotable y adquiere las proporciones que lo singularizan.

\section{EL SANTUARIO}

Antes de analizar la relación entre templo y naturaleza, conviene aclarar unas cuestiones previas. Si bien nos hemos referido a la «casa de dios» utilizando el término templo, es bueno recordar que ésta es una palabra de origen latino, que procede de templum, vocablo que los romanos utilizaban para referirse más bien a un espacio sagrado. Tal aclaración etimológica nos permite recordar que en el mundo antiguo la «casa de dios» no era una estructura aislada, sino que era parte de un complejo religioso mayor: el santuario, 
que solía aparecer con mucha antelación respecto de la construcción del templo, el que más bien se erigía cuando el recinto sagrado ya estaba consolidado ${ }^{4}$.

A partir de las definiciones que nacen del estudio del concepto de espacio sagrado en la Antigüedad, realizadas al amparo de investigaciones de religiones comparadas, podemos recordar que un santuario se origina de la voluntad del hombre de consagrar, «recortar», un terreno a la propiedad de un dios en particular. Para el hombre religioso, la construcción de un santuario implicaba la consagración de un lugar, creando orden en medio del caos profano; "para vivir en el Mundo hay que fundarlo, y ningún mundo puede nacer en el 〈caos〉 de la homogeneidad y de la relatividad del espacio profano» (Eliade, 26). Al consagrar un espacio, el hombre religioso recreaba el orden, el cosmos. ¿Qué orden? El impuesto por sus dioses a la hora de dar origen al mundo. Así el arquitecto, como un "pequeño dios", imitaba los mitos cosmogónicos, de modo tal que en el mundo antiguo entendemos un santuario como una imago mundi.

Para los griegos antiguos, el «orden» comenzaba a partir de la consagración del terreno que ocupaba un altar al aire libre, el témenos, y dentro de los límites de este último se hallaba el hieron o "lugar sagrado», el equivalente al templum romano. Todas las culturas antiguas dieron un valor importantísimo al ritual de demarcar un lugar, hacer la separación entre espacio sagrado y espacio profano. En Grecia, el témenos era de contornos definidos y claramente delimitados, generalmente por un muro que contenía las construcciones del santuario; valga la aclaración, ya que cuando en la actualidad se visitan los sitios arqueológicos, ese elemento en la práctica ha desaparecido, lo que es extrapolable a otros santuarios del mundo antiguo, como los egipcios ${ }^{5}$ o los mesopotámicos.

El recinto sagrado delimitado por muros estrechaba horizontalmente el paisaje, estableciendo unos límites fijos en los que el templo y el altar se interrelacionaban con otras construcciones, tales como los propileos y docenas de monumentos votivos, en su mayoría esculturas que "poblaban el recinto sagrado y subrayaban la escala humana peculiar de la arquitectura griega [...] El templo, en este sentido, era el lugar de reunión entre lo humano y lo divino. Al mismo tiempo que los humanos están encumbrados por la orgullosa y mesurada elevación de las columnas, las deidades descendían al nivel de la visibilidad humana» (Kostof, 226).

Para poder entender el santuario como un todo y comprender las relaciones que establecía con el paisaje circundante, conviene profundizar en los elementos que lo conformaban. Basándonos en Martienssen, el témenos estaba constituido, además del altar y el templo, por: los propileos, el Tesoro, la Stoa y las esculturas autónomas.

Los propileos (o propileo) eran la entrada monumental del santuario, un verdadero edificio-puerta. Su forma también, al igual que el templo, se remonta a los pórticos dobles de los palacios micénicos: «de este modo, su planta se componía de dos pórticos unidos en un solo volumen global, con columnas in antis ${ }^{6}$; la separación entre estos porches estaba dada por una pared con vanos, cuyo plano se aproximaba al del muro o períbolo del témenos» (Martienssen, 108). Ambas caras, interior y exterior, eran iguales

Un ejemplo de ello lo encontramos en Olimpia, donde el culto a Zeus puede rastrearse hasta fines de siglo $\mathrm{X}$ a.C., unos tres siglos antes de la construcción del primer templo monumental (Spawforth).

5 Casi imperceptibles frente a la magnitud de las estructuras pétreas, los restos de los muros que cerraban los complejos funerarios egipcios pasan hoy inadvertidos a los viajeros.

6 Donde las paredes laterales de la naos se proyectan en forma tal que encierran dos columnas y forman un porche. 
y parecían un pequeño templo con frontón. En casos excepcionales, como en la Acrópolis de Atenas, los propileos adquieren mayor complejidad y monumentalidad.

Podemos intuir que la construcción de un verdadero edificio para señalar una puerta va más allá del aspecto puramente plástico. Más bien estamos hablando de una estructura arquitectónica que denota uno de los rituales más importantes y trascendentales de todas las religiones, el «rito de tránsito», el pasar un umbral que nos conduce de un terreno profano a uno sagrado.

El Tesoro es habitual encontrarlo en los grandes santuarios interestatales panhelénicos, con su forma similar a la de un pequeño templo (con columnas in antis), constituyéndose en una suerte de homenaje que hacían las grandes ciudades a dichos recintos religiosos. Se utilizaba para la recepción de armas, ofrendas y otros tributos provenientes de las peregrinaciones a los templos sagrados.

La Stoa era un pórtico exento, de una o dos naves, de estructura muy simple, pero de uso eminentemente público, en lo que radicaba su particularidad. Su origen se remonta a los santuarios, donde cumplía una función pública un tanto vaga, ya como cobijo para días de lluvia, ya como alojamiento nocturno para peregrinos y pacientes que habían sido conducidos ahí para ser curados.

Esta estructura pronto se secularizó y fue parte activa de la vida en ciudad, convirtiéndose en uno de los edificios más característicos de la arquitectura griega, y era habitual encontrarla sobre todo en torno al ágora. Manteniendo su uso eminentemente público, servía para sesiones de justicia, asambleas del Consejo de la Ciudad y banquetes oficiales, a la vez que era el lugar donde se daban a conocer noticias públicas. Fue también espacio de encuentro de pensadores y estudiosos que, rodeados de alumnos, recorrían sus naves.

Dentro del área sagrada constituía una unidad arquitectónica más, desempeñando un importante papel definitorio del esquema general, ya que junto con el muro del santuario, no sólo delimitaban, sino que conformaba un motivo decorativo; formaba el fondo sobre el que se destacan con mayor nitidez los edificios esenciales del templo o el altar.

Por último estaban las esculturas autónomas ${ }^{7}$, las que, repartidas en el área del témenos y recortándose sobre el fondo arquitectónico de los grandes templos, solían «acompañar» visualmente a los peregrinos que se desplazaban por las calzadas sagradas, cumpliendo de esa forma el rol de acentuar la escala humana del conjunto. Excepciones a esta forma las encontramos, por ejemplo, en la colosal escultura de bronce de Atenea Promakos (la Campeona), realizada por Fidias para la Acrópolis de Atenas.

Esas esculturas solían ser ofrendas religiosas que eran costeadas por las polis o por ciudadanos particulares a modo de exvotos. En los santuarios panhelénicos, donde se disputaban competencias deportivas en honor a los dioses, las esculturas más habituales eran los kouroi, que representaban a los atletas vencedores.

En el estudio de los santuarios griegos, uno de los aspectos que ha creado más debate es la manera en que los elementos que lo conformaban se ordenaban e interactuaban dentro del témenos. A la luz de los levantamientos de los sitios arqueológicos realizados en los siglos pasados, se pensaba que al interior del santuario reinaba el caos, y durante décadas se soslayó ese tema, pensando que no existía ningún orden subyacente que lo explicara. Hoy, en cambio, hay un consenso general entre los investigadores en que debió existir un orden, y que el emplazamiento de un templo no era fortuito, sino que

Para diferenciarlas de las que formaban parte del juego escultórico del templo, es decir que no eran exentas. 
se originaba, como veremos más adelante, por una hierofanía ${ }^{8}$ (Eliade). Autores como Norberg-Schulz (Arquitectura occidental y Genius Loci), Scully y Martin proponen que los santuarios poseían una estructura que estaba determinada por el carácter del lugar, el topos, dejando de lado algún orden de tipo geométrico, como han propuesto otros autores, entre los cuales destaca Doxiadis. Él establece una distribución de las masas de los edificios según un sistema de coordenadas polares, de modo que estuvieran óptimamente distribuidas de forma homogénea, a partir de un punto de vista privilegiado, que era el acceso al témenos, es decir los propileos?
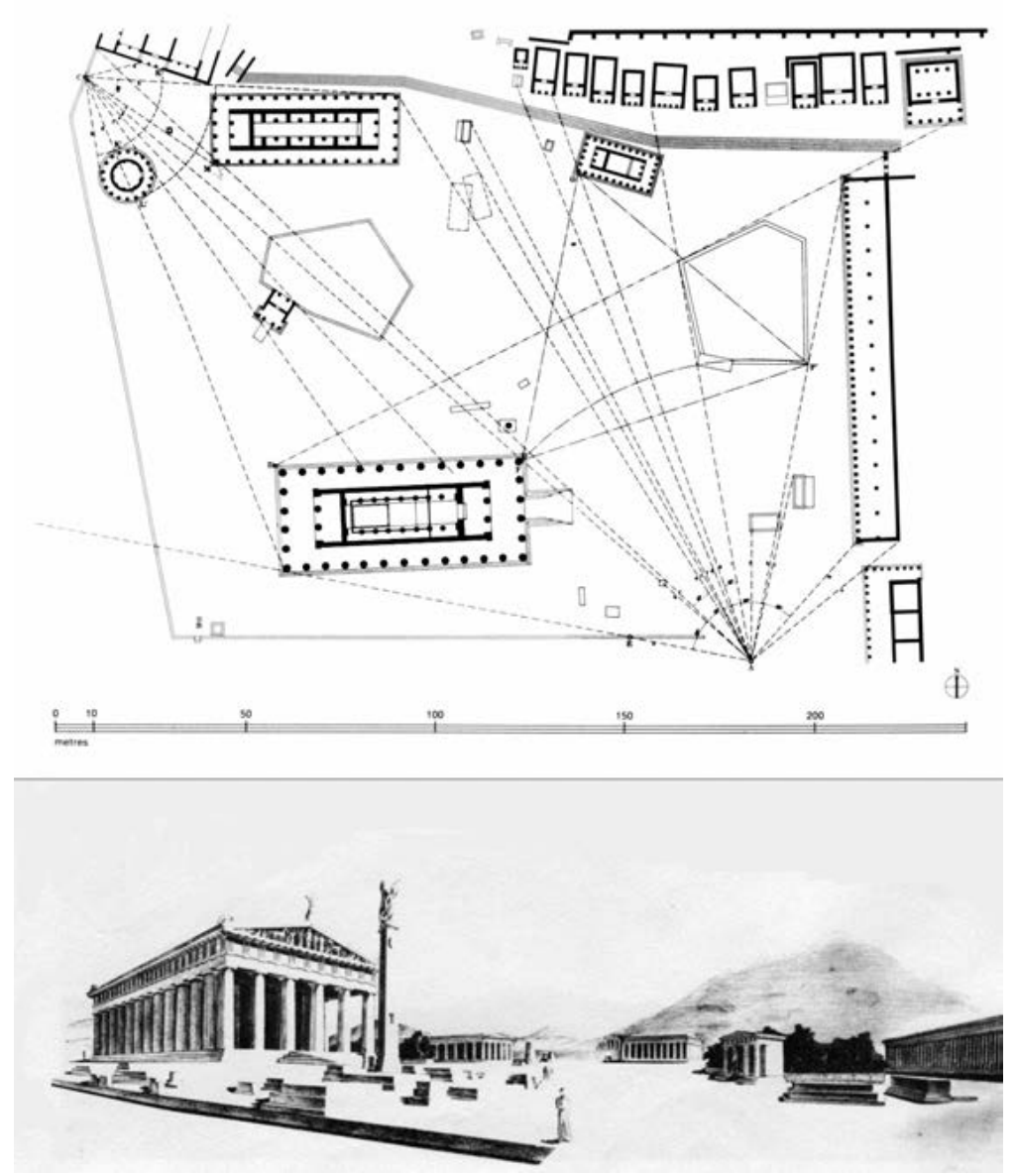

Imagen 3. Estudio de las coordenadas polares propuestas por Doxiadis para el conjunto de edificios que conforman el santuario de Olimpia. Se toman como punto de origen de las coordenadas dos de los propileos del conjunto. En la imagen inferior apreciamos la reconstrucción de la vista que debía tener el peregrino al acceder por los propileos que se encuentran al sur, donde en primer plano destaca el templo de Zeus y al fondo el consagrado a Hera (esquema intervenido por el autor a partir de Doxiadis).

$8 \quad$ Manifestación de lo sagrado (Eliade).

9 Los edificios estaban ordenados dentro del arco de máxima visibilidad individual y emplazados a intervalos rítmicamente relacionados. Ello está basado en la concepción griega de un universo circular y en la capacidad de la visión humana de abarcar, como realmente sucede, un arco de 180 grados (Scully). 
A pesar de que el tema recién planteado merece una exposición más detallada, no es el fin del presente artículo, que busca profundizar en la relación que establecen los santuarios interurbanos con su entorno paisajístico.

Como lo dice su nombre, entenderemos por santuarios interurbanos aquellos que no están insertos en el tejido urbano de una ciudad en particular. La mayoría de ellos eran frecuentados por los habitantes de una comunidad de ciudades; sólo unos pocos, los de mayor renombre, adquirían la categoría de panhelénicos, como Delfos, Olimpia, Istmia y Nemea ${ }^{10}$. Aun así debemos acotar más la cuestión y establecer que nos referiremos a los santuarios que adquirieron su configuración definitiva en la época clásica griega ${ }^{11}$ y no a los de la época helenística, más tardíos y que son el reflejo de una manera distinta de «ser» en el mundo.

Al constatar que para el hombre religioso la naturaleza tiene características heterogéneas, comprendemos entonces que el emplazamiento de un edificio no era casual, sino que estaba determinado por una serie de consideraciones vinculadas a la geomancia. Basándonos en los estudios que se han hecho de dichos emplazamientos, observamos algunas contantes que se establecían entre el santuario y su entorno, que pasaremos a detallar.

\section{GENIUS LOCI}

El genius loci, el reconocimiento y expresión del espíritu del lugar particular, ha sido el legado más perdurable de Grecia en el campo del diseño paisajístico. La arquitectura simbolizó el orden universal. El paisaje existente carecía, por lo general, de un orden aparente. Los griegos no sólo armonizaron dos cosas que parecían opuestas, sino que confirieron al conjunto un significado que la civilización está empezando a aceptar ahora como no exclusivo de Grecia.

Geoffrey Jellicoe y Susan Jellicoe, El paisaje del hombre

La caracterización antropomórfica de los lugares naturales proviene de los griegos. Para ellos los distintos ámbitos de su entorno topográfico poseían una personalidad claramente reconocible, una individualidad, entendida como una manifestación de un "carácter arquetípico». De esa manera, el paisaje se llenó de significados psíquicos y religiosos, que le daban un contenido espiritual, ya que los griegos consideraban la naturaleza dotada «con un espiritualizado contenido humano» (Giedion).

El origen de esa proyección antropomórfica podría derivarse de una antigua concepción religiosa, el animismo, que reconocía en los elementos que conformaban el mundo la presencia de un anima.

Para caracterizar y reconocer esa proyección existencialista en el paisaje utilizamos la expresión latina genius loci. Este término se deriva de la creencia religiosa romana del genio, que a su vez se origina en el concepto griego del daimon ${ }^{12}$, el cual, si bien se apli-

10 Entre otras cosas en común, en estos centros religiosos se celebraban competencias deportivas de carácter religioso, entre las que destacan las realizadas en el santuario consagrado Zeus: los Juegos Olímpicos.

11 Período Clásico: 450-325 a.C.

12 Espíritu benéfico que protegía a cada individuo. 
caba a cada ser humano, luego derivó a la naturaleza, reconociendo que cada rincón del paisaje griego estaba protegido por un genius loci.

Así, se entendía que las características topográficas de un determinado enclave natural se debían a la manifestación del genio protector del lugar o a la expresión del «carácter» de un dios. Así, existía una suerte de determinismo que, entendido como hierofanía, le permitía al hombre reconocer a quién se debía consagrar determinado paisaje; si en un lugar la naturaleza se manifestaba en toda su grandiosidad, era propicio para un santuario a las antiguas divinidades de la tierra, las diosas Deméter y Hera; si en un lugar la vida se sentía como una totalidad armoniosa, el sitio debía estar consagrado a Zeus; o bien, si en determinado lugar los hombres se habían agrupado en una polis, el área sagrada se consagraba a la diosa Atenea (Norberg-Schulz, Arquitectura occidental).

\section{EL ANTECEDENTE MÍTICO-HISTÓRICO}

La peculiaridad de la configuración de un enclave natural no sólo evocó asociaciones de carácter existencial en el hombre, sino también otras de tipo mítico-histórico; no sabemos en qué momento de la etapa formativa de la religión griega el hombre creyó reconocer en ciertos lugares del paisaje circundante el marco de fondo de los mitos que configuraban sus creencias, asociación que también predestinaba y antecedía el emplazamiento de un santuario. "El terreno no era neutral. El lugar donde se iba a erigir el templo no era una cuestión de elección arbitraria. La elección se había hecho antes de que hubiera ningún templo por lo que una vez ocurrió en este terreno» (Kostof, 218-220).

Algunas de esas asociaciones son fáciles de comprender, por ejemplo el emplazamiento del hogar del panteón de dioses en el monte Olimpo, que reconocía en él la condición de ser el axis mundi por excelencia del mundo griego, al corresponder a la cumbre más alta de Grecia. Otras relaciones son más crípticas y el arquitecto requería de un conocimiento acabado de la cosmogonía y del lugar donde las historias de los dioses habían ocurrido; como por ejemplo el santuario panhelénico más famoso, Olimpia, que está situado en el corazón de la Élide, al sur de Grecia, en un llano y frondoso valle regado por el río Alfeo, en el cual el templo dedicado a Zeus está levantado donde, según el mito, el dios habría sido criado, tras ser trasladado por los atletas dorios desde Ida, para protegerlo y evitar que fuera devorado por su propio padre, Cronos.

Al parecer la sacralidad de un emplazamiento se veía reforzada por la cantidad de mitos que allí habían ocurrido, que solían ser más de uno. En la misma Olimpia son alrededor de un centenar de ellos los que presagiaban el surgimiento del santuario y de las actividades religiosas que allí se realizaban. De hecho los Juegos Olímpicos que le dieron fama fueron instaurados para reconocer al fundador de una de las más importantes estirpes míticas griegas, Pélope, ya que en este lugar derrotó al cruel rey Enómao, cuyo palacio se emplazaba donde luego se erigió el santuario. El héroe venció al rey, al retarlo a una carrera de carros tirados por caballos, que ganó gracias a la intervención de Zeus, quien habría inspirando a Hipodamia, hija del rey y enamorada de Pélope, para que retirara las clavijas de las ruedas del carro de su padre (Graves). Este mito fundacional reafirma la victoria de los valores de la justicia, de la humanidad y del respeto a las leyes divinas. El héroe sería recordado, dándole su nombre a esa región de Grecia: el Peloponeso. 
No sólo el paisaje griego manifestaba estas hierofanías míticas, sino que también surgían a lo largo de las costas del Mediterráneo, por donde sus héroes realizaron sus periplos. Un hermoso ejemplo lo encontramos en Sicilia, donde en las cercanías de la colonia de ultramar de Akragas ${ }^{13}$, sobre un acantilado, surgió un conjunto religioso conocido en la actualidad como el Valle de los Templos. En el extremo más oriental y culminando un camino ascendente, se encontraba uno de ellos al parecer consagrado a Hera Lacinia ${ }^{14}$, que debe su apodo a sus orígenes míticos vinculados al héroe Lacinio. Las variantes del mito no dejan claro si Lacinio fue héroe o villano. Según algunos fue un rey de Corcira, que en un acto de generosidad habría acogido a Crotón, que había sido desterrado; según otra versión habría sido un bandido, hijo de la ninfa Cirene, que habría intentado robar algunos bueyes a Heracles, cuando el héroe volvía de Eritia con los rebaños de Geriones. Heracles le habría dado muerte y en arrepentimiento habría construido el Templo de Hera Lacinia, en el promontorio homónimo.

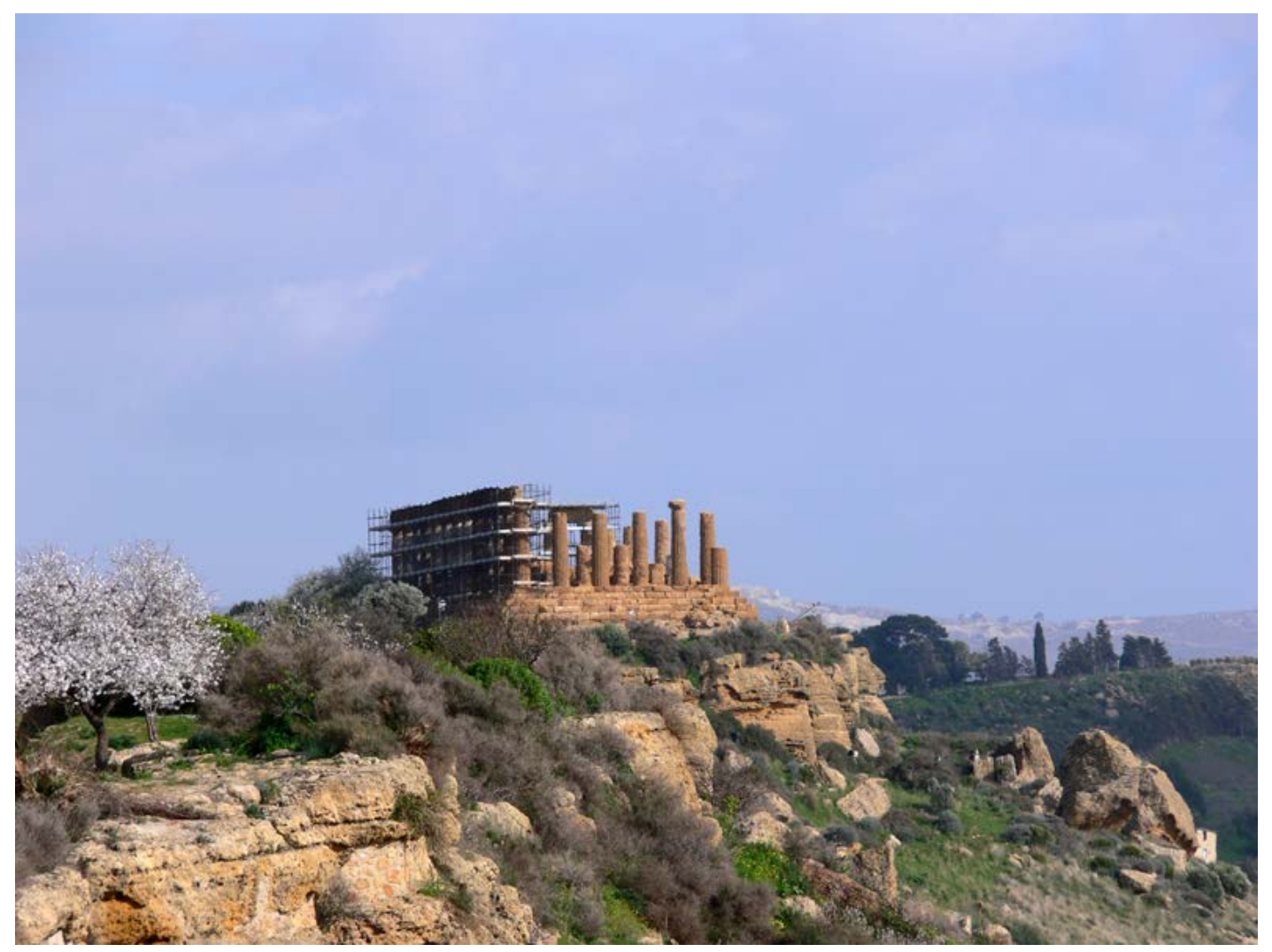

Imagen 4. Recortándose sobre el paisaje siciliano, al final de un risco que domina el mar y el valle, surge el templo expiatorio levantado por Heracles en honor a Hera en Akragas (hoy Agrigento), finales del siglo V a.C., Italia.

Fuente: fotografía del autor.

13 Posteriormente colonia romana conocida como Agrigento.

14 Levantado a finales del siglo V a.C., es un templo dórico hexástilo, con 13 columnas laterales. 


\section{EL CONTRASTE CON LA NATURALEZA}

No debemos, pues, considerar el templo meramente como una cosa en sí misma, un bello caparazón independiente de su emplazamiento, ni tampoco asumir que el emplazamiento tiene un valor pintoresco primordial, como si el terreno fuera un elemento neutral que utilizaran los constructores para añadir interés visual a su propia creación.

Spiro Kostov, Historia de la arquitectura

El templo griego era una construcción claramente artificial, donde sus colores y su forma geométrica estructurada en base a ángulos rectos se destacaban en abierto contraste con la naturaleza circundante. Permanecía enclavado en el paisaje como algo aparte, renunciando a fundirse con las formas azarosas de la naturaleza, no queriendo traicionar su carácter, fruto del juego de elaboradas abstracciones formales y matemáticas.

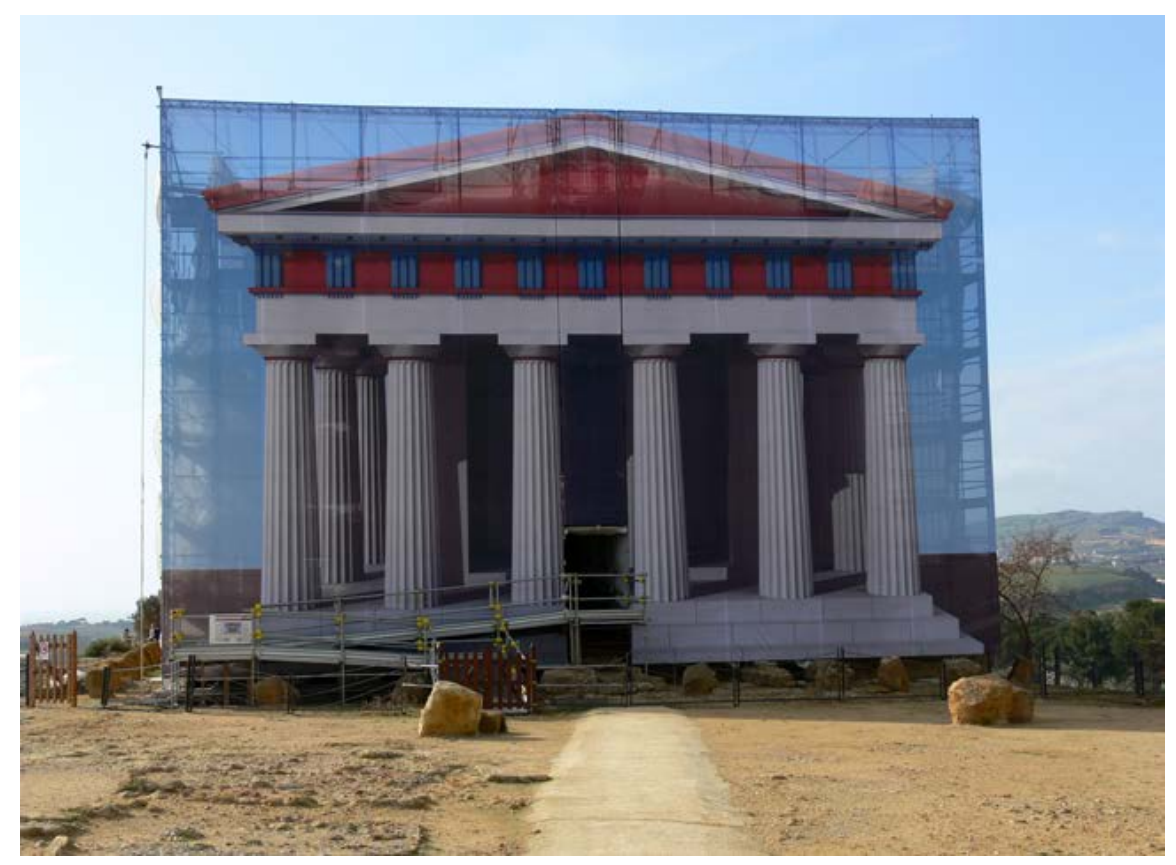

Imagen 5. Vista del templo de la Concordia en proceso de restauración, donde la malla que lo protege recrea la posible apariencia policromada que tuvo al momento de su consagración, aproximadamente en el 430 a.C. Valle de los Templos, Akragas, Sicilia, Italia. Fuente: fotografía del autor.

De alguna manera el templo griego se convierte en un «faro" de la racionalidad del hombre, que durante siglos vivió inmerso y a merced de las fuerzas oscuras y ancestrales de la naturaleza, como queriendo así proclamar con orgullo el triunfo de los logros humanos. Ese meditado contraste entre «lo natural y lo inventado» es la base de la arquitectura religiosa griega (Kostof). Por ello no será casualidad que los griegos escojan y 
privilegien paisajes accidentados y llamativos ${ }^{15}$, permitiendo que el contraste sea mayor y logrando así que se realcen los opuestos ${ }^{16}$.

El santuario de Sounión se convierte en un paradigma de lo expuesto y de lo que algunos autores griegos recomendaban sobre el emplazamiento ideal de un templo, el que debía estar ubicado en un lugar elevado y ostentoso, ya que de esa manera se tenía una visión lejana del edificio, lo que inspiraba al rezo (Spawforth). Quizás en términos teóricos debemos entender que tal condición reforzaba el carácter de axis mundi que representaba todo templo. Sounión es un cabo que se abalanza sobre el mar Egeo, constituyéndose en el punto más meridional del Ática y en uno de los primeros pedazos de tierra firme continental que veían los marinos que navegaban rumbo a El Pireo ${ }^{17}$, momento preciso en el que debían agradecer al dios del mar por haberles permitido llegar a tierra firme. Es claro entender entonces que el santuario que se construyó en su cima, a más de 60 metros sobre el nivel del mar, estuviera consagrado a Poseidón ${ }^{18}$. El Egeo suele ser en ciertas épocas del año bastante traicionero y no hay quizás experiencia más reveladora acerca de la fuerza de la naturaleza que encontrarse en una tormenta marítima, no hay momento más aleccionador, con respecto a sentirse a merced de las fuerzas de la naturaleza, de lo que dan cuenta la mayoría de los mitos cosmogónicos de la Antigüedad, donde el mar representa el «caos»; más que nunca entonces entendemos la metáfora del templo griego como «faro de racionalidad», que se yergue en franco contraste con las fuerzas indomables de la naturaleza.

El templo griego, al contraponerse al paisaje, refuerza también su carácter de edificioescultura. Muchos autores han discutido y afirmado que era concebido fundamentalmente como una presencia exterior, como una arquitectura de cuerpos plásticos (NorbergSchulz, Arquitectura occidental). No es necesario explayarse mucho para afirmar que la búsqueda de una rica especificidad de espacios interiores es escasa en Grecia y que, por el contrario, ésa será una característica de la arquitectura romana, donde el desarrollo de variados y complejos espacios interiores dará un giro a la historia de la arquitectura.

Esta concepción que privilegiaba la presencia exterior del edificio estaba resaltada por el peristilo ${ }^{19}$, que levantaba el templo contra el vacío; era arquitectura en el espacio y sólo tenía como fondo el paisaje natural ${ }^{20}$. Su configuración de volumen plástico quedaba realzada por la erección de la construcción sobre un pedestal escalonado, que más allá

15 Cabe señalar que esto podía variar de acuerdo al orden arquitectónico del templo. También el estilo en el cual estaba construido implicaba tácitamente una ubicación: lugares altos y escarpados para el orden dórico, emplazamientos bajos y pantanosos para los de orden jónico.

16 Ése es un principio que ha sido utilizado también por otros pueblos de la Antigüedad, sobre todo en el Lejano Oriente. Sería imposible concebir un jardín japonés que imitara las formas azarosas de la naturaleza, sin el contraste que le otorgan las formas ortogonales de los pabellones y del muro que lo circunda.

17 Puerto de la ciudad de Atenas.

18 En el santuario también existió un templo jónico consagrado a Atenea Sunias, del cual apenas quedan restos arqueológicos.

19 Perímetro de columnas que rodea algunos templos, los llamados perípteros.

20 Algunos autores ven en ello también una imagen cosmológica. En sus poemas Homero y Hesíodo (siglo VIII y VII a.C.) describen que la tierra y el cielo se mantenían separados por altos pilares o por Atlas. El cielo se entendía como un tejado sólido extendido sobre la tierra, hecho de hierro o bronce según las metáforas poéticas. Nuevamente nos encontramos ante una imagen que refuerza el carácter del templo entendido como una imago mundi (Spawforth). El entender el cielo de la naos como una metáfora de los cielos era habitual y explica el porqué muchos templos en su interior tenían escaleras monumentales, que al igual que en muchos de sus equivalentes egipcios y a manera de axis mundi conducían a las partes altas de la construcción (aunque desconocemos qué función ritual cumplían). 
de su función práctica era el elemento que definía horizontalmente el espacio y servía de plataforma a la estructura, evitando que pareciese surgir de la tierra misma. La forma pura del edificio expresaba la intención de no querer fundirse con el paisaje circundante, declarando su independencia de las formas naturales, realzando de ese modo su artificialidad.

Finalizando el punto haremos mención de otro magnífico enclave que encontramos en la Magna Grecia. Ubicado en las montañas del noroeste de Sibila se encuentra Segesta, un santuario inacabado ${ }^{21}$, en pleno corazón de la antigua población itálica de los élimos (elymoi), «uno de los testimonios más emocionantes de la penetración del espíritu griego en una sociedad autóctona de Occidente» (Stierlin). Segesta fue la rival de Selinonte. La ciudad élima se sintió siempre amenazada por la dinámica y próspera colonia, por lo que se alió con Atenas, lo cual explicaría la fuerte influencia cultural y artística griega que se manifiesta en su santuario religioso.

El único templo del santuario fue iniciado hacia el 425 a.C., y se desconoce a quién estaba consagrado. La construcción quedó inacabada debido a la infortunada expedición llevada a cabo con su aliada Atenas, que buscando atacar Siracusa terminó en un desastre del cual los élimos no se pudieron reponer ${ }^{22}$.

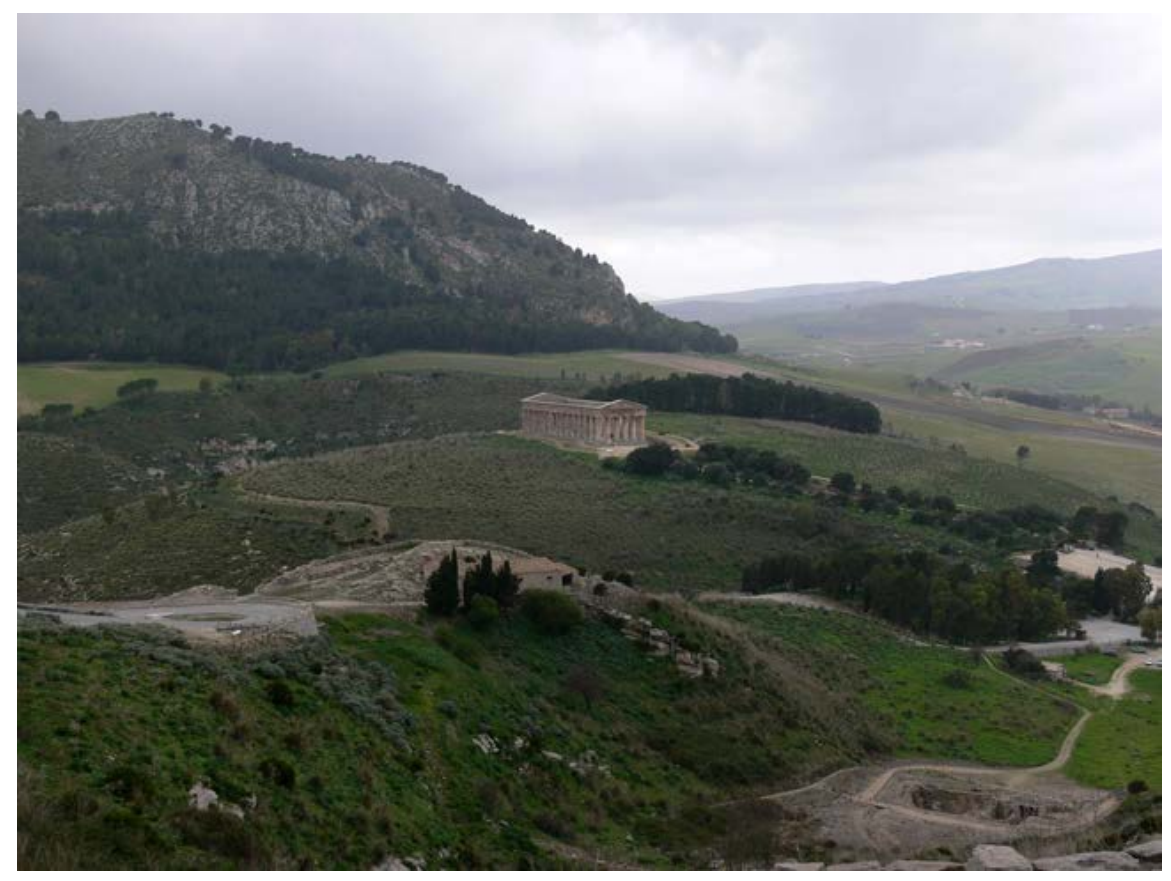

Imagen 6. Levantado en uno de los emplazamientos más espectaculares del sur de Italia, el templo de Segesta fue erigido por los élimos a partir del año 425 a.C. Sicilia. Fuente: fotografía del autor.

$21 \quad$ El templo al parecer nunca tuvo unas naos, ni cubiertas.

22 Algunos teóricos dicen que fue destruido en la guerra, otros en cambio lo atribuyen a exigencias específicamente religiosas de los élimos, "podría tratarse de un períbolo cultural hipetral, destinado ya sea a la celebración de los ritos religiosos sobre altares móviles o en materiales perecederos bajo la «cóncava〉 bóveda del cielo', como habría dicho Homero, antes que el humosa oscuridad del naos» (Stierlin). 
Dominando una aislada colina, las elegantes formas del estilo dórico del templo se recortan contra imponentes y ásperos acantilados de piedra, permitiéndonos apreciar el contraste entre sus «formas racionales» y las formas azarosas de la naturaleza. Para acceder al recinto sagrado había que recorrer una calzada serpenteante, que frente a criterios más pragmáticos parece excesiva; quedando claro que primaban criterios puramente estéticos, los que permitían al espectador, a medida que ascendía por la calzada, contemplar el templo desde distintos ángulos, siempre con vistas escorzadas que resaltaran el volumen de la construcción.

\section{APOLO EN DELFOS}

Quizás sea oportuno citar el santuario de Delfos, ya que es un magnífico ejemplo a la hora de recapitular los aspectos antes señalados. Situado a unos veinte kilómetros del golfo de Corinto, en uno de los emplazamientos más espectaculares y dramáticos de Grecia, encaramándose en las faldas del célebre monte Parnaso, el conjunto arquitectónico pone de manifiesto la gran tensión existente entre las dos fuerzas opuestas, la naturaleza y el hombre. En Delfos «el drama de la existencia humana está representado simbólicamente en términos arquitectónicos» (Norberg-Schulz, Arquitectura occidental, 33).

Podemos ya deducir que éste es el emplazamiento perfecto para honrar a una diosa vinculada a la tierra, de allí que se haya consagrado a Gea, la divinidad primitiva de la fertilidad y madre de la naturaleza. El culto nació al borde del precipicio, al fondo del cual moraba su hija Pitia, serpiente-dragón, encarnación ctónica por antonomasia. Desde lo profundo de la caverna emanaban vapores telúricos ${ }^{23}$, a los que se les atribuía valores proféticos, una verdadera hierofanía. Tales efluvios embriagaban a los hombres y les proporcionaban capacidades adivinatorias, es por ello que una sacerdotisa o pitonisa se sentaba al borde de la caverna y cayendo en trance pronunciaba sus oráculos ${ }^{24}$.

La tradición mítico-histórica nos señala que en ese lugar se presentó el dios Apolo, a quien fue consagrado luego el santuario, y dio muerte a la hija de la madre tierra. Claramente ese acontecimiento se convierte en una alegoría del pensamiento griego, donde $\mathrm{Apolo}^{25}$, dios de la luz, de esa luz que nos libera de la ignorancia representada por las tinieblas, pone su pie y da muerte a Pitía, la que encarna las fuerzas de la naturaleza, que en «épocas oscuras» sometieron al hombre bajo su yugo. El templo de Apolo que se levantará en el lugar será literalmente un «faro» de la razón del hombre que triunfa y se impone a las fuerzas de la naturaleza, encarnada por el accidentado entorno; es el hombre instaurando su propio orden por sobre el de la naturaleza, es el hombre recreando el cosmos divino, es el hombre realizando arquitectura.

El triunfo de Apolo, nacido de una «violencia necesaria» sobre la feroz primitividad simbolizada por Pitón, pasa a través de una expiación que es testimonio de la voluntad de

23 La falla geológica por la cual emanaban dichos vapores, debido a movimientos sísmicos de épocas remotas, hoy no existe.

24 El oráculo se encontraba en un nivel inferior respecto del basamento del templo. Reforzando metafóricamente la idea, sostenida por los griegos y los pueblos antiguos en general, de que las profundidades estaban vinculadas al poder profético.

25 Otra corriente de interpretación atribuye al dios Apolo el don de la profecía. 
instituir la civilización y el derecho contra la barbarie de los «tiempos oscuros», hasta encarar la razón y el equilibrio, el saber y el genio creativo como prerrogativas y dones del dios (Durando, 207).

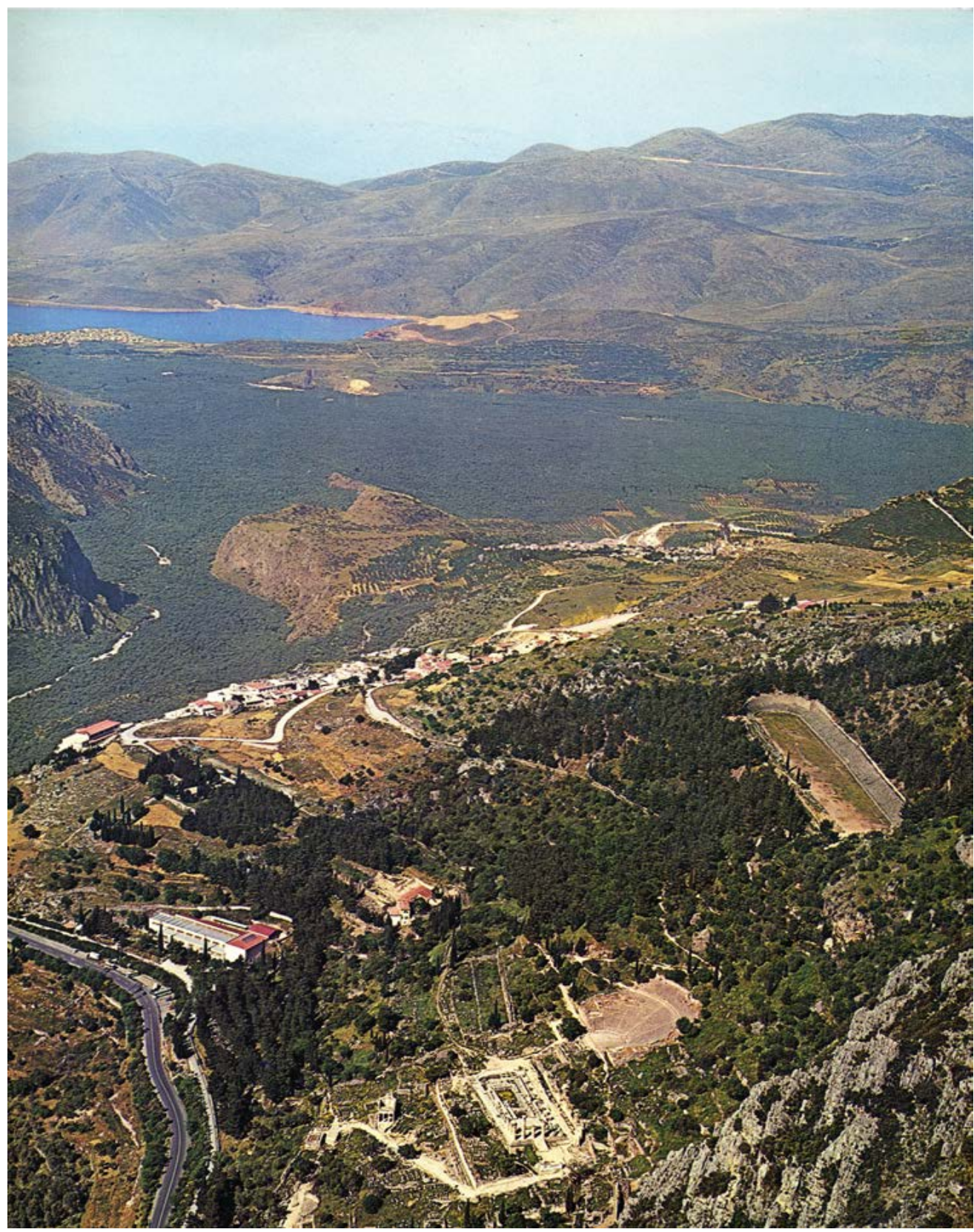

Imagen 7. Vista aérea del valle del Pleistos que desemboca en el Golfo de Corinto. En la parte inferior de la fotografía vemos el santuario de Delfos, donde destacan los restos del templo de Apolo, precedido por la calzada sagrada, que rodeada de los tesoros serpentea por las faldas del monte Parnaso. Fuente: fotografía tomada del libro de Themelis. 
El carácter oracular y la fama consecuente de sus profecías convirtieron a Delfos en el centro del quehacer griego, por lo que fue considerado el «ombligo del mundo» ${ }^{26}$. Ese centralismo religioso, pero también político, es fácil de entender; en el lugar se legitimaban o se prohibían, por boca del dios, todos los actos de las polis griegas.

Una piedra que señalaba el lugar de la muerte de la serpiente se convirtió en un ónfalo, uno de los axis mundi más potentes del mundo griego. Es la victoria de Apolo interpretada como una hierofanía, que le reveló al hombre un "punto fijo» a partir del cual ordenar su mundo, en medio de una naturaleza que hasta entonces le había resultado hostil.

Apolo había asumido, pues, los símbolos de la tierra y los había integrado en una visión total, completamente nueva, de la naturaleza y el hombre. Como dios de la poesía y la sabiduría, Apolo asumió el papel mediador de los significados existenciales, y la recepción más o menos pasiva de una verdad impuesta desde lo alto o preestablecida, es sustituida por la voluntad fáctica de una intervención creativa y por la inspiración humana (NorbergSchulz, Arquitectura occidental, 35).

\section{A MODO DE CONCLUSIÓN}

En los tiempos actuales, en que se ha revitalizado el concepto de «arquitectura del paisaje» y en que en el ámbito teórico se discute acerca de la «crisis de la lugaridad», se vuelve pertinente releer bajo nuevos parámetros la manera en que las culturas antiguas encontraron su «lugar» en el mundo. Los griegos antiguos, más que ningún otro pueblo, centraron su atención ya no tanto en la relación que establecían sus edificios sagrados con las estrellas o con los cuerpos celestes distantes, sino en la problemática de la tierra y de las fuerzas que la caracterizan.

En la medida en que entendamos que la filosofía griega, desconfiando de la percepción sensible (aisthesis), objetivó la belleza, remitiéndola al ámbito del pensamiento (noûs), es que podemos comprender que el templo era una entelequia matemática nacida en el «mundo de las ideas», un puro juego de orden, simetría y proporciones canónicas. Tal idealización matemática sólo se humanizaba cuando, por medio de un acto hierofánico, encontraba su lugar en la naturaleza, su locus; es en este momento también, cuando se singularizaba, es decir cuando el templo se hacía reconocible. La idealización se completaba en el momento en que se producía la «lugarización» del templo.

26 El templo contenía la piedra onfalos o huevo cósmico, que simbolizaba el centro del mundo. Era una piedra cónica, de primordial importancia simbólica, que cubría probablemente el bothros original, o gruta de las ofrendas de la Gran Diosa. 
82

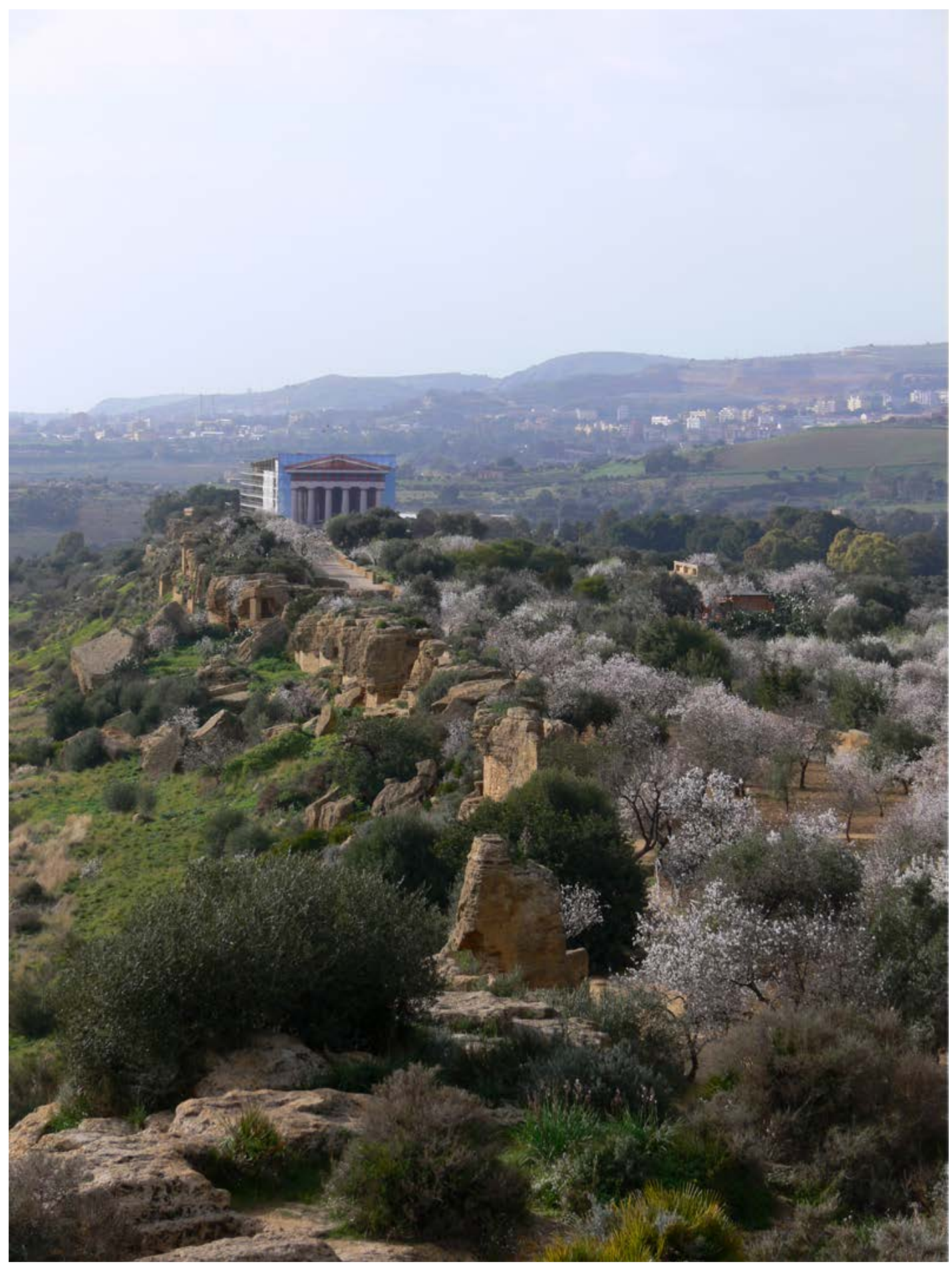

Imagen 8. Risco donde se emplaza el Valle de los Templos de Akragas. Al fondo se aprecia el templo de la Concordia. Sicilia, Italia. Fuente: fotografía del autor. 


\section{REFERENCIAS}

Akerman, James. La Villa. Forma e ideología de las casas de campo. Madrid: Ediciones Akal, 1990. Medio impreso.

Doxiadis, C. A. Architectural Space in Ancient Greece. Cambridge: The Massachusetts Institute of Technology, 1972. Medio impreso.

Durando, Furio. Grecia antigua, el alba de Occidente. Barcelona: Ediciones Folio, 1977. Medio impreso.

Eliade, Mircea. Lo sagrado y lo profano. Barcelona: Editorial Labor, 1988. Medio impreso.

Giedion, Sigfried. La arquitectura, fenómeno de transición. Barcelona: Editorial Gustavo Gili, 1969. Medio impreso.

Graves, Robert. Los mitos griegos. Madrid: Editorial Alianza, 1993. Medio impreso.

Jellicoe, Geoffrey y Susan Jellicoe. El paisaje del hombre. Barcelona: Editorial Gustavo Gili, 1995. Medio impreso.

Kostof, Spiro. Historia de la arquitectura. Tomo I. Madrid: Editorial Alianza, 1996. Medio impreso.

Martienssen, R. D. La idea del espacio en la arquitectura griega. Buenos Aires: Editorial Nueva Visión, 1958. Medio impreso.

Martin, Roland. Architettura greca. Milán: Electa Editrice, 1978. Medio impreso.

Masiero, Roberto. Estética de la Arquitectura. Madrid: Visor, 2003. Medio impreso.

Norberg-Schulz, Christian. Arquitectura occidental: la arquitectura como historia de formas significativas. Barcelona: Gustavo Gili, 1983. Medio impreso.

—. Genius Loci. Paesaggio Ambiente Architettura. Milán: Editoriale Electa, 1996. Medio impreso.

Scully, Vincent. The Earth, the Temple and the Gods. Londres: New Haven, 1962. Medio impreso.

Spawforth, Tony. Los templos griegos. Madrid: Ediciones Akal, 2007. Medio impreso.

Stierlin, Henri. Grecia, de Micenas al Partenón. Barcelona: Taschen, 1998. Medio impreso.

Themelis, Petros. Delphi, The archaeological Site and the Museum. Athens: Ekdotike Athenon, 1980. Medio impreso.

Recepción: 10 de agosto de 2010

Aceptación: 25 de enero de 2011 